\title{
Noninvasive Mechanical Ventilation Knowledge Level of the Nurses: A Questionnaire Survey in a Tertiary Care Training and Research Hospital
}

\author{
Merve Tarhan ${ }^{1}$, Özcan Hançer ${ }^{1}$, Fulya Polat ${ }^{1}$, Songül Akbaş Gökduman ${ }^{1}$, Levent Dalar ${ }^{2}$
}

${ }^{1}$ Yedikule Chest Diseases and Chest Surgery Training and Research Hospital, İstanbul

${ }^{2}$ Department of Chest Diseases, İstanbul Bilim University Faculty of Medicine, İstanbul

\begin{abstract}
Objective: The correct use of necessary equipment is the key for a successful noninvasive mechanical ventilation (NIMV) practice. Trained health care personnel are important part of the practice. The current study was conducted to that end, with the aim of determining the level of knowledge about NIMV of nurses working in a training and research hospital as descriptive.

Methods: The study was conducted with 147 nurses who are working at Yedikule Chest Diseases and Thoracic Surgery Training and Research Hospital in Istanbul. Questionnaire form of 36 questions prepared by investigators was used to collect data. For the analysis of the results, numerical, percentages, Mann-Whitney U and Kruskal Wallis tests were used.'

Results: $40.8 \%$ nurses had received training about NIMV. By contrast, $24.5 \%$ stated that they had learned NIMV practices on their own. The lowest rate $(26.5 \%)$ of correct answered question was "disadvantages of oronasal mask". The most answered statement as true was "Face masks should be established to the patient's face with no gaps for prevention of leaks and the mask should be worn not to pressure on nasal bridge" (78.9\%). Female and postgraduate nurses" total scores obtained from NIMV questions were higher than others and were statistically significant $(\mathrm{p}<0.05)$.

Conclusion: The effective NIMV practices requires trained personnel. Nurses who have active role in NIMV practices should receive basic training in this topic. How will be started treatment, indications, who will be responsible for follow-up and points to take into consideration are mentioned clearly in the training program. This training programme should include processing of clinical experience as well as theoretical information.
\end{abstract}

Keywords: Knowledge, noninvasive ventilation, nursing, respiratory failure

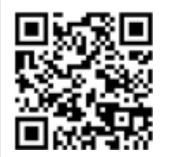

Received Date: 30.05 .2015 Accepted Date: 20.07.2015 Available Online Date: 09.11.2015 DOI: 10.5152/ejp.2015.14633

Corresponding Author Merve Tarhan

E-mail: mmervetarhan@gmail.com

-Available online at www.eurasianjpulmonol.com 4.0 International License.

\section{INTRODUCTION}

Non-invasive mechanical ventilation (NIMV) is a method that provides positive pressure respiration support through a mask without using an endotracheal tube (1). When compared with invasive mechanical ventilation (IMV), NIMV decreases the duration of stay in the hospital and intensive care unit, morbidity, and mortality in patients with acute and chronic respiratory failure (2). All patients with acute or chronic respiratory failure who do not show contraindications are NIMV candidates, provided that the necessary equipment and a trained team are available (3).

The most appropriate management of NIMV can be performed when all the team members are experienced and well-equipped. Physicians should carefully differentiate the patients that may successfully respond to NIMV administration from those who may urgently require intubation. In many countries, respiratory therapists are responsible for selecting an appropriate mask, determining the most proper placement of the mask on the face, setting the ventilator to alleviate respiratory distress, and initiating NIMV (4). In countries such as Turkey, where there are no respiratory therapists, the initiation of NIMV therapy and patient follow-up are performed by doctors and nurses $(5,6)$. Therefore, nurses are required to monitor the patients and to be knowledgeable about the identification and prevention of potential problems. 
Successfully performed NIMV is associated with the right patient, the right place, the right ventilation, the right mask, and equipped personnel. In the case of the absence or failure of one of these factors, the effective management of NIMV may be compromised. Trained medical personnel are an important part of the application of NIMV. To our knowledge, there has not yet been a study that evaluates the knowledge of nurses regarding NIMV in the literature. From this viewpoint, this study was conducted to define the knowledge level of NIMV of nurses working in a tertiary pulmonology hospital.

\section{METHODS}

This descriptive study was conducted in July 2013 with nurses working in Yedikule Chest Diseases and Chest Surgery Training and Research Hospital. Because of the frequent rotation of in-hospital applications, all the nurses were obliged to participate actively in NIMV administration; therefore, they were included in the questionnaire.

The data were collected through a questionnaire prepared by the researchers. The questionnaire consisted of 35 questions that examined the nurses' demographics and knowledge about NIMV. For the questions that evaluated the nurses' level of knowledge, correct answers were considered as 1 point, and wrong answers were considered as 0 points. The minimum score was 0 points and the maximum score was 41 for the questionnaire. All the nurses working at the hospital were invited to fill out the questionnaire, and their verbal consent was obtained after they were informed about the study. Of a total of 210 nurses working at the hospital, 147 nurses (70\%) who agreed to participate in the study and who were not on leaves, such as maternity or sick leave, comprised the research sample. For this study, written permission was received from the Secretariat General of the İstanbul Fatih Public Hospitals Association.

\section{Statistical Analysis}

Analysis of the results was performed using the Statistical Package for the Social Sciences (SPSS) program for Windows (version 16.0, 2007, SPSS Inc.; Chicago, IL, USA), with the average, standard deviation, percentage, Mann-Whitney $U$, and Kruskal-Wallis one-way analysis of variance tests. Results were within the $95 \%$ confidence interval, and a significance level of $p<0.05$ was adopted.

\section{RESULTS}

The mean age of the participants was $32.45 \pm 7.59$ (range 19-53) years. Of the nurses who participated in the research, $85.7 \%$ were female, $60.5 \%$ were married, and $46.3 \%$ had bachelor's degrees. In addition, $38.8 \%$ of the nurses were working in the internal medicine clinic. While $27.9 \%$ of the nurses had $1-5$ years of professional experience, $45.6 \%$ had the same term of institutional experience. Furthermore, $40.8 \%$ of the nurses had previously received training on NIMV, and $24.5 \%$ had learned NIMV administration by themselves (Table 1 ).

The total average score obtained from the NIMV questions was $19.32 \pm 4.51$ (in the points range of 7-33). Statistical significance was found between gender and educational level and the average score obtained from noninvasive questions $(p<0.05)$. Female nurses and nurses who had post-graduate degrees had higher average scores (Table 1).

For the places in which NIMV can be administered, $89.8 \%$ of the nurses stated intensive care, $88.4 \%$ stated inpatient services, $70.7 \%$ stated emergency services, $61.2 \%$ stated the home, $60.5 \%$ stated intermedi-
Table 1. Distribution of nurses' socio-demographic features in percentage values and comparison of the mean scores obtained from the whole questionnaire with these features

\begin{tabular}{|c|c|c|c|c|}
\hline Feature & $\mathbf{n}$ & $\%$ & $\begin{array}{l}\text { Questionnaire } \\
\text { score }\end{array}$ & p \\
\hline \multicolumn{5}{|l|}{ Gender* } \\
\hline Female & 126 & 85.7 & 76.98 & \multirow{2}{*}{0.037} \\
\hline Male & 21 & 14.3 & 56.14 & \\
\hline \multicolumn{5}{|l|}{ Marital status* } \\
\hline Married & 89 & 60.5 & 70.24 & \multirow{2}{*}{0.183} \\
\hline Single & 58 & 39.5 & 79.78 & \\
\hline \multicolumn{5}{|l|}{ Educational status* } \\
\hline Medical vocational high school & 24 & 16.3 & 57.12 & \multirow{4}{*}{0.011} \\
\hline Associate degree & 45 & 30.6 & 68.81 & \\
\hline Undergraduate degree & 68 & 46.3 & 78.59 & \\
\hline Postgraduate degree & 10 & 6.8 & 106.65 & \\
\hline \multicolumn{5}{|l|}{ Place of working** } \\
\hline Internal medicine & 57 & 38.8 & 67.42 & \multirow{7}{*}{0.087} \\
\hline Surgical clinic & 23 & 15.6 & 73.30 & \\
\hline Emergency unit & 16 & 10.9 & 63.12 & \\
\hline Others & 12 & 10.9 & 89.62 & \\
\hline Intensive care unit & 11 & 8.2 & 102.64 & \\
\hline Outpatient clinic & 12 & 8.2 & 63.46 & \\
\hline Operating room & 16 & 7.5 & 85.81 & \\
\hline \multicolumn{5}{|l|}{ Occupational experience ${ }^{* *}$} \\
\hline Less than 1 year & 8 & 5.4 & 49.12 & \multirow{6}{*}{0.536} \\
\hline $1-5$ years & 41 & 27.9 & 71.67 & \\
\hline $6-10$ years & 26 & 17.7 & 83.08 & \\
\hline $11-15$ years & 27 & 18.4 & 74.57 & \\
\hline $16-20$ years & 23 & 15.6 & 75.00 & \\
\hline 21 years and above & 22 & 15.0 & 74.91 & \\
\hline \multicolumn{5}{|l|}{ Institutional experience ${ }^{* *}$} \\
\hline Less than 1 year & 15 & 10.2 & 60.67 & \multirow{6}{*}{0.555} \\
\hline $1-5$ years & 67 & 45.6 & 74.78 & \\
\hline $6-10$ years & 21 & 14.3 & 86.19 & \\
\hline $11-15$ years & 14 & 9.5 & 65.43 & \\
\hline 16-20 years & 18 & 12.2 & 71.94 & \\
\hline 21 years and above & 12 & 8.2 & 78.08 & \\
\hline \multicolumn{5}{|l|}{ State of training* } \\
\hline Yes & 60 & 40.8 & 78.44 & \multirow[b]{2}{*}{0.292} \\
\hline No & 87 & 59.2 & 70.94 & \\
\hline \multicolumn{5}{|l|}{ Sources of training ${ }^{* *}$} \\
\hline Seminar, course, etc. & 34 & 23.1 & 80.00 & \multirow{6}{*}{0.156} \\
\hline Brochure, book, etc. & 14 & 9.5 & 79.57 & \\
\hline By oneself & 36 & 24.5 & 71.49 & \\
\hline From physicians & 19 & 12.9 & 75.50 & \\
\hline From nurses & 11 & 7.5 & 41.14 & \\
\hline I do not know & 33 & 22.4 & 78.29 & \\
\hline \multicolumn{5}{|l|}{ n: number, \%: percentage } \\
\hline
\end{tabular}




\begin{tabular}{|c|c|c|c|c|c|}
\hline Reduction of symptoms & 99 & 67.3 & Nurses knowing none of them correctly & 28 & 19 \\
\hline Increasing functional state & 40 & 27.2 & Nurses knowing 1 of them correctly & 91 & 61.9 \\
\hline Decreasing respiration activity & 31 & 21.1 & Nurses knowing 2 of them correctly & 20 & 13.6 \\
\hline Providing patient comfort & 25 & 17 & & & \\
\hline Extending lifetime & 21 & 14.3 & & & \\
\hline \multicolumn{6}{|l|}{ NIMV advantages } \\
\hline Elt provides infection control & 84 & 57.1 & Nurses knowing none of them correctly & 18 & 12.2 \\
\hline It requires preparation for a long time & 7 & 4.8 & & & \\
\hline \multicolumn{6}{|l|}{ NIMV contraindications } \\
\hline Cardiac or respiratory arrest & 114 & 77.6 & Nurses knowing none of them correctly & 7 & 4.8 \\
\hline Gastrointestinal bleeding & 67 & 45.6 & Nurses knowing 1 of them correctly & 83 & 56.5 \\
\hline Non-respiratory organ failure & 40 & 27.2 & Nurses knowing 2 of them correctly & 33 & 22.4 \\
\hline Cardiogenic pulmonary edema & 26 & 24.5 & Nurses knowing all of them correctly & 24 & 16.3 \\
\hline Obesity/hypoventilation patients & 10 & 6.8 & & & \\
\hline \multicolumn{6}{|l|}{$\begin{array}{l}\text { Pressure-related complications in } \\
\text { NIMV application }\end{array}$} \\
\hline Claustrophobia & 38 & 25.9 & & & \\
\hline \multicolumn{6}{|l|}{ Advantages of oronasal mask } \\
\hline Less leakage & 75 & 51 & Nurses knowing none of them correctly & 39 & 26.5 \\
\hline Vomiting, aspiration & 43 & 29.3 & Nurses knowing 1 of them correctly & 85 & 57.8 \\
\hline Adjustable for comfort & 41 & 27.9 & Nurses knowing 2 of them correctly & 16 & 10.9 \\
\hline Difficulty in speaking and coughing & 38 & 25.9 & Nurses knowing all of them correctly & 7 & 4.8 \\
\hline Acute respiratory failure & 22 & 15.0 & & & \\
\hline Injury in the nasal root & 17 & 11.6 & & & \\
\hline \multicolumn{6}{|l|}{$\begin{array}{l}\text { Points to be considered before } \\
\text { NIMV application }\end{array}$} \\
\hline Use of appropriate mask & 120 & 81.6 & Nurses knowing none of them correctly & 23 & 15.6 \\
\hline Sitting position at the angle of 45 degrees & 101 & 68.7 & Nurses knowing 1 of them correctly & 91 & 61.9 \\
\hline Cooperation with device & 96 & 65.3 & Nurses knowing all of them correctly & 33 & 22.4 \\
\hline Impaired general health condition & 37 & 25.2 & & & \\
\hline Being fed $1 \mathrm{~h}$ ago & 35 & 23.8 & & & \\
\hline
\end{tabular}




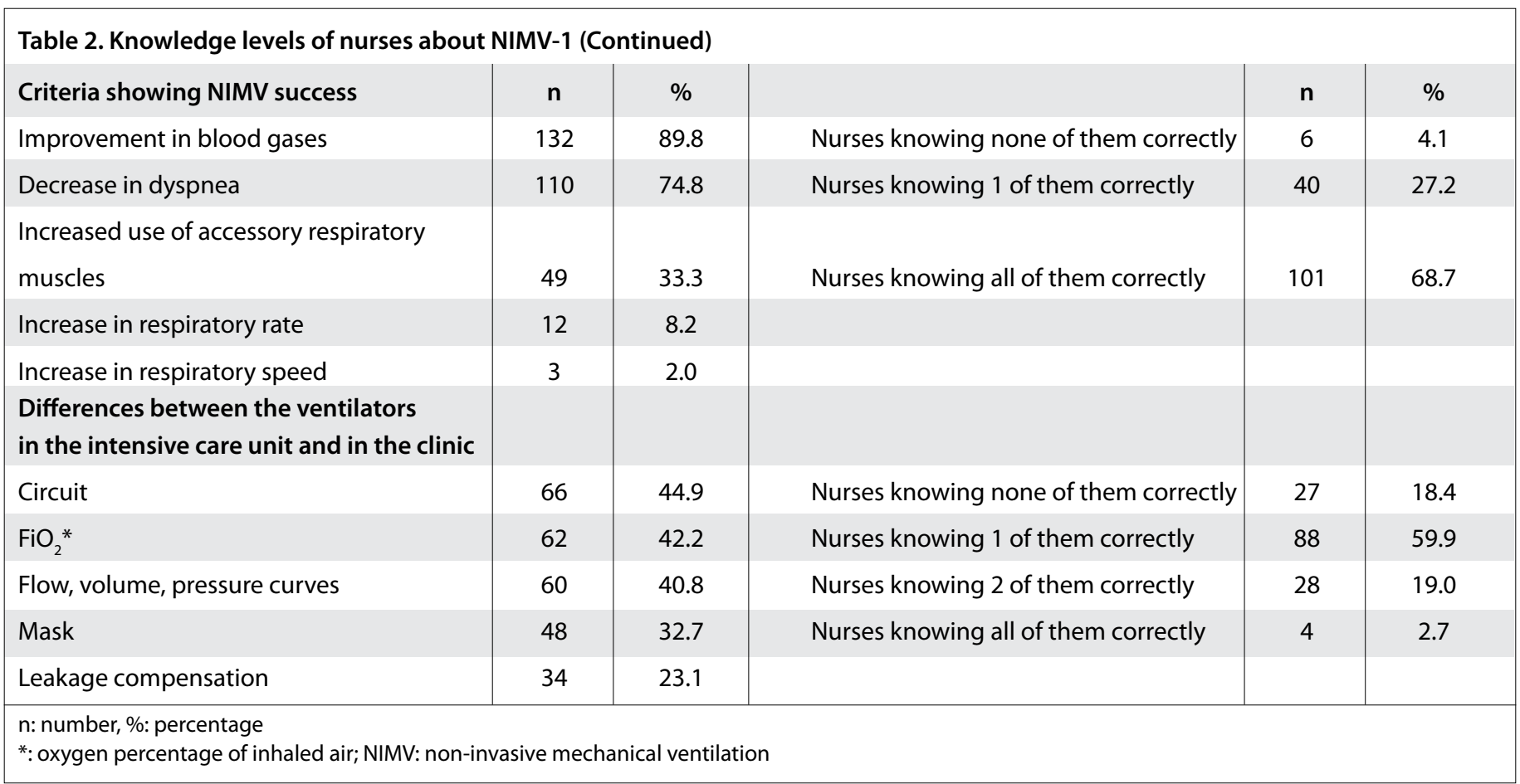

ate intensive care units, and $10.2 \%$ stated operating rooms. The nurses named the features of a good NIMV mask as having low leakage (77.6\%), being non-allergenic (53.7\%), being robust (51.7\%), having various sizes available (44.2\%), being non-traumatic (41. 5\%), being washable (35.4\%), and being low-priced (21.8\%).

The short-term objectives of NIMV were the elimination of symptoms (67.3\%), reducing the work of breathing (21.1\%), and ensuring patient comfort (17\%). In total, $5.4 \%$ of the nurses succeeded in identifying all of the short-term objectives. Ensuring infection control (57.1\%) and patients being able to cough easily on their own (49\%) were the advantages of NIMV; the percentage of nurses who did not know any of the correct answers was $12.2 \%$. It was found that $24.5 \%$ of the nurses considered cardiogenic pulmonary edema as an NIMV contraindication. The complications related to pressure in NIMV administration are gastric distention (68.7\%), irritation of the eyes (49\%), and irritation of the pneumothorax (35.4\%); $19 \%$ of the nurses answered all the questions regarding these complications correctly. Additionally, $26.5 \%$ of the nurses answered all the questions about the advantages of the oronasal incorrectly; the most correctly answered advantage was that it has less leakage (51\%). It was revealed that $22.4 \%$ of the nurses did not know any of the issues to be considered during the pre-NIMV administration. Also, $68.7 \%$ of the nurses succeeded in identifying all the criteria of NIMV success. Of all the options, the least correctly answered question was the difference between ventilators used in intensive care units and ventilators used in clinics (2.7\%) (Table 2).

It was revealed that the most correctly answered question by $78.9 \%$ of the nurses was "in order to prevent leakage, the mask should be placed on the patient's face without leaving any gap and should be taped properly in order to prevent applying pressure on the nasal root"; the least correctly answered question by $3.4 \%$ of the nurses was "the filter of the NIMV device must be replaced every $240 \mathrm{~h}$ ". In addition, $75.5 \%$ of the nurses correctly answered the question stating that "if no humidifier or bacteria filter had been used for an ARB-positive patient, I would use the device after making sure that the device is properly sterilized under proper conditions by contacting the sterilization team," $74.8 \%$ of the nurses chose the answer stating that "during NIMV application, I make sure that the patient sits on the bed or a chair at a 45 degree angle," and $74.8 \%$ of the nurses chose the answer stating that "a bacterial filter is inserted between the device and the connection"; these statements were the most correctly answered statements (Table 3).

\section{DISCUSSION}

The results that were obtained from the questionnaire revealed that the overall knowledge level of the nurses regarding NIMV was low. It was found that they obtained high scores on questions about clinical practice; they scored moderately on questions about device equipment; and they scored poorly on questions about theoretical issues, such as indications. This shows that the nurses did not know what application is performed for what purpose. Performing an application without knowledge represents a failure to comply with an evidence-based nursing approach. If the basic principles that provide the basis for health, disease, or treatment are not understood, holistic nursing is beside the point.

Ensuring that the medical personnel who are in charge of NIMV management are experienced and skilled is the key component for the success of the procedure. Carlucci et al. (7) showed that the success of the application of NIMV is associated with the experience and capabilities of the personnel. In this study, more than half of the nurses stated that they had not received any training on NIMV, and the majority stated that they had learned information about NIMV on their own. Thus, it is obvious that the development of related training programs is required. According to Elliott et al. (8), training programs on NIMV should include subtopics such as understanding the need for NIMV, accurate and efficient placement of the mask, the correct use of ventilation equipment, understanding and implementing the 
Table 3. Knowledge levels of nurses about NIMV-2

Questions evaluating knowledge of NIMV

To prevent leakage, the facial mask must be placed on the face of the patient without leaving a space;

it must be taped to prevent pressure on the nasal root.

If no humidifier or bacteria filter had been used for an ARB-positive patient, I would use the device after making sure that the device is properly sterilized under proper conditions by contacting the sterilization team.

I make sure that the patient sits on the bed or a chair at a 45-degree angle.

The bacteria filter is inserted between the device and the connection.

NIMV can be interrupted for medication, nutrition, and physiotherapy.

The exhalation port on the circuit helps the air from expiration to move out of the mask.

The reason for the use of an oronasal mask, despite the greater advantages of a nasal mask, is that COPD patients generally breathe by mouth.

I give inhaler drugs to patients receiving NIMV with a T-connection.

If an exhalation port is not available in the NIMV mask, the carbon dioxide level of the patient would be expected to increase continuously.

The asphyxia valve is the space that enables the patient to receive air in the event of any device problems.

Mortality is lower in patients who receive NIMV than in patients who receive invasive mechanical ventilation.

Device maintenance must be performed at least once a year.

The asphyxia valve is on the mask.

While giving inhaler drugs to patients receiving NIMV, the inhaler connection must be between the moisturizing filter and the patient.

Calibration of NIMV devices must be performed once a year.

The moisturizing filter is placed between the exhalation port and the patient.

The pressure line port is used for the measurement of pressure values returning from the patient.

The pressure line port is between the mask and the circuit.

Moisturizing and bacteria filters are changed when they are contaminated.

The filter of the NIMV device must be changed every $240 \mathrm{~h}$.

ARB: Acid-resistant bacteria culture; COPD: chronic obstructive pulmonary disease; NIMV: non-invasive mechanical ventilation

ventilator settings, the general maintenance of the ventilator, and solving problems in unfavorable situations. In this study, women were found to be more successful than men. As the level of education increased, the nurses' level of knowledge regarding NIMV also increased. It is necessary to consider these issues when training programs are prepared.

Non-invasive mechanical ventilation is used with increasing frequency in chronic obstructive pulmonary disease (COPD), in acute heart failure, and in acute respiratory failure. The most important aim of NIMV is to avoid endotracheal intubation, and thus, to reduce complications related to IMV (9). NIMV has other long-term goals, such as prolonging the patient's life expectancy, improving the quality of life, improving sleep time/quality, and improving the patient's functional status (3). Also, in this study, the questions related to alleviating the symptoms, reducing the work of breathing, and ensuring the patient's comfort examined the short-term objectives of NIMV. Only $5.4 \%$ of the nurses succeeded in identifying all the short-term objectives. It is believed that this lack of information may cause delays in the nurses' recognition of expected changes in a patient during NIMV application.
Non-invasive mechanical ventilation has important advantages compared with IMV. Antonelli et al. (10) compared IMV and NIMV in acute respiratory failure in their study; they reported that in the NIMV group, nosocomial pneumonia occurred less frequently, the duration of hospitalization in the intensive care unit and hospital was shorter, and the treatment was more effective in selected cases than IMV. The rate of participants knowing all the advantages of NIMV was $18.4 \%$. Nurses who know the advantages of NIMV can contribute to the development of a team attitude for considering all patients presenting with respiratory failure as NIMV candidates.

Studies demonstrate that NIMV decreases the need for intubation and extends the lifetime when used on appropriate patients. For instance, in a randomized controlled study performed on patients with COPD exacerbation, although a significant decrease was observed in the rates of intubation with the use of NIMV, $16 \%$ of patients using NIMV were intubated (11). Similarly, in a study investigating acute cardiogenic pulmonary edema, the use of NIMV was found to reduce the need for intubation (12). In a prospective observational study conducted in France, NIMV failed in $38 \%$ of patients in different disease groups (13). It is not realistic to expect that NIMV will decrease 
the need for intubation and be successful in all patients. Inappropriate ventilator pressures, inexperienced health teams, and the general state of the patient's health are the main factors affecting the success of NIMV. Patient selection and follow-up are highly important for reducing NIMV failure $(14,15)$. Mass and Masip (16) listed contraindications for NIMV as conditions such as respiratory or cardiac arrest as well as situations in which it is impossible to put on the mask, such as agitation and inability to cooperate, uncontrolled vomiting or gastrointestinal bleeding, total upper airway obstruction, face trauma, multiple organ failure, progressive severe respiratory failure, and pregnancy. In another study, cardiac or respiratory arrest, non-respiratory organ failure, face trauma, upper airway obstruction, inability to provide airway patency, abundant secretion, and high risk of aspiration were listed as contraindications for NIMV. Among the choices, the first three contraindications were correct. It was a striking result that $24.5 \%$ of nurses specified cardiogenic pulmonary edema as a contraindication, which was an important mistake.

International consensus reports recommend that the NIMV procedure should be performed in well-equipped emergency units and intensive care units where close monitoring is possible because intubation will be required as a result of failed NIMV administration. In the consensus report of the American Thoracic Society, it is stated that NIMV can be applied in the clinic by an experienced team if the $\mathrm{pH}$ value is $\geq 7.30$ in the presence of respiratory distress associated with acute exacerbation of COPD. However, for patients whose general health state and arterial blood gas values have not improved in the first hours, this application can be considered to be accurate, provided that it is possible to transfer patients to the intensive care unit before respiratory distress worsens (17). Although the NIMV procedure is initiated in emergency units in many hospitals, patients are followed up in intensive care units. However, it is seen that patients are sometimes followed up in general clinics because of an insufficient number of beds in intensive care units. The best follow-up is performed in intermediate intensive care units, where a nurse is responsible for only three patients. Therefore, the patient's need for monitoring, the patient capacity that the unit can monitor, technical opportunities, and an adequate number of skilled and experienced staff are the most important factors for the determination of NIMV location (4). The most ideal location for long-term NIMV treatment is the patient's home because it decreases hospital cost, increases the quality of life, and enables the patient to integrate with society (18). One of the most notable findings of the study was that the nurses specified that NIMV could be applied in the operating room. However, NIMV is not performed in operating rooms.

Non-invasive mechanical ventilation provides positive pressure or ventilator support to the lungs through an interface without being invasive to the tracheal respiratory tract (16). Interfaces for NIMV include a mouthpiece, nasal mask, nasal pads, oronasal mask, total face mask, and helmet mask (19). The appropriate choice of interface for NIMV is very important for the success of the treatment (3). Hess (20) defined the desirable features of an interface as having minimal dead space, being transparent, light, and easily fixable, giving only slight pressure on the face, having less leakage, being disposable or easily cleanable, being non-allergic, being inexpensive, having different sizes, being adjustable to facial anatomy and quickly removable, having anti-asphyxia mechanisms, and being compatible with ventilators. In the study, nurses indicated non-allergic and strong masks with less leakage to be preferable. They might have considered a mask with less leakage to be good for efficient treatment because appropriate masks reduce air leakage. Moreover, they might have chosen strong and non-allergic masks for extended use because of the high cost of NIMV masks.

In NIMV, one of the most important causes of treatment failure is the choice of an inappropriate mask. Nasal masks require the mouth to be kept closed, and accordingly, they also require good cooperation and an open nasal passage. Therefore, these masks are generally used for long-term treatment of chronic respiratory failure. On the other hand, an oronasal mask provides less air leakage and higher ventilation pressure than a nasal mask. Because it allows the patient to breathe by mouth, it requires less patient cooperation. Therefore, an oronasal mask is mostly preferred for acute respiratory failure. However, an oronasal mask is more disturbing than a nasal mask. It prevents speaking and oral intake, and it can cause claustrophobia and gastric distension (21). Although the use of oronasal masks was common in our hospital, one of the questions that was answered less correctly was related to the advantages and disadvantages of such masks (4.8\%). Knowing the advantages and disadvantages of masks will help nurses to take precautions to prevent the development of mask-related complications during the follow-up of patients who undergo NIMV.

One of the problems encountered in NIMV is air leakage (22-24). When a mask is chosen in consideration of the patient's personal features and is fixed appropriately, air leakages are reduced to an almost non-existent level. Taping the mask tightly can increase ventilation by preventing air leakages; however, it must be considered that taping too tightly can cause skin injuries (2). Injuries occurring in the nasal root are among the most frequently observed skin complications (24-26). A mask with a forehead protector can be used to decrease the pressure on the nasal root. The nasal root can be taped; however, this will not work if serious injuries develop (20). To prevent air leakage and decrease skin injuries, there must be a space between the bands of the mask and the face through which two fingers can be inserted (26). In this study, the question that was most frequently answered correctly was related to the way to fix the mask (78.9\%). Because this question was related to the nurses' daily practices, it is natural that they knew the answer.

Complications associated with positive pressure in the study were pneumothorax, gastric distention, and irritation of the eyes. All of these complications can be reduced by decreasing pressure. Pneumothorax, which is an important complication, is rarely seen. Particularly, irritation of the eyes can be avoided by being careful to prevent air leakages (27). The rate of the occurrence of aerophagia and gastric distention in patients using NIMV varies between $5 \%$ and $40 \%$. Based on recent evidence, NIMV must be performed in a half-sitting position $0.5 \mathrm{~h}$ after eating to prevent gastric distention (2). Most of the nurses knew about gastric distention, which is a complication related to pressure, and the necessity for the patient to sit in a position at the angle of 45 degrees during the procedure, which shows the consistency between theoretical knowledge and practice.

Another question that was answered correctly by the nurses was about the criteria demonstrating the success of NIMV support. Mas and Masip (16) defined the criteria for failure of NIMV as the lack of decrease in respiratory rate, lack of improvement in $\mathrm{pH}$, lack of increase in oxygen level, lack of decrease in carbon dioxide level, and 
symptoms of fatigue. If NIMV support is successful, a decrease is seen in the respiratory rate and in the use of accessory muscles, and a remarkable improvement is observed in blood gas values (4). The criteria showing the success of NIMV can be observed and might have been much better known because they are practical.

There are three alternatives for the administration of inhaler drugs in patients undergoing NIMV. In the first, the patient is weaned from the ventilator and a nebulizer or metered-dose inhaler is applied; these are accepted as standard methods. In the second, an inhaler drug is given through a nebulizer placed between the mask and the circuit. In the third, a metered-dose inhaler is inserted between the air chambered mask and the circuit (28). For nebulization, the nebulizer is directly attached to the NIMV mask with a T-junction (29). The rate of correct answers given to this question by responsible nurses was $61.2 \%$. Nurses should take care regarding the administration techniques of inhaler drugs because these techniques may differ depending on the needs of the patient.

In NIMV, a low level of dead space, which is necessary for preventing re-inhalation of carbon dioxide, can be provided with an exhalation port located on the circuit $(30,31)$. Schettino et al. (32) demonstrated that oronasal masks with exhalation ports caused less re-inhalation of carbon dioxide compared to total face masks. In patients who cannot remove their masks because of the breakdown of the ventilator or a power interruption, the risk of asphyxia is an alarming situation. With recent developments in oronasal masks, the bands can be loosened immediately. Anti-asphyxia valves on the mask can be deployed and re-inhalation can be prevented. Moreover, in total face masks, there is an asphyxia valve that is opened when the airway pressure decreases below $3 \mathrm{~cm} \mathrm{H}_{2} \mathrm{O}$ (33). The questions about the asphyxia valve and exhalation port were related to patient safety. As in all treatment methods, undesirable situations related to patient safety can occur in NIMV. The knowledge of nurses responsible for patient follow-up on the mechanisms that can be used in undesirable situations was at a moderate level.

Filters represent a type of NIMV equipment. A bacteria filter must be inserted between the ventilator and the pipe. Although the moisturizing filter differs depending on the model of the device, it is placed between the exhalation port and the patient to moisturize the patient's nasal and oral mucosa during NIMV application (34). With a moisturizing filter, the development of complications due to flow can be prevented. In a study conducted in Turkey, moisturizing filters having the feature of bacteria filtration could be used without any contamination for 72 hours, and no growth was observed on the ventilator sides of the moisturizing/bacterial filters in culture results (35). In the study, $75.5 \%$ of nurses stated that when they did not use a moisturizing filter or bacteria filter in a patient with positive ARB, they contacted the sterilization team to request that the device be sterilized correctly and under proper conditions, and they used the device after this process. Their accurate knowledge of the placement of the bacteria filter shows that they had practical knowledge of the reason for the use of the filter. Nurses having knowledge of filters and their proper use can reduce the risk of infection that can develop when many different patients use a device.

During NIMV application, NIMV can be interrupted for medication, nutrition, and physiotherapy. Saltürk et al. (1) showed in their study that during NIMV application, under the supervision of experienced personnel, patients removing the mask of their own accord and being off-themask for a short time do not hinder the success of NIMV; instead, the adaptation of the patients is increased. This question was answered well by the nurses, since it requires knowledge about implementation (5).

One important issue is equipment maintenance. Maintenance and calibration of the device should be performed once a year if there is no unusual situation. However, when a new breathing circuit or a mask is purchased and if the device has a mask or circuit feature, mask and circuit calibration should be performed by technical services. In our study, the nurses' rate of knowledge regarding the issues related to equipment maintenance was low.

Invasive intensive care ventilators are often used for NIMV. Invasive mechanical ventilators have very highly technical features, and their ability to provide high pressure, $\mathrm{FiO}_{2}$, and detailed monitoring are their main advantages. Their basic disadvantages are that they are costly and they declare false emergencies because of clinically insignificant small air leaks. Studies have shown that NIMV is as effective as IMV for the treatment of acute respiratory failure (36). The least correctly answered question by the nurses was the differences between intensive care ventilators and service ventilators; the percentage of nurses who answered this question correctly was $2.7 \%$. The reason for this situation might be that not all nurses have intensive care experience, and thus, they have not performed any application of intensive care ventilators.

\section{CONCLUSION}

It is obvious that the nurses' knowledge of NIMV, a therapy that is frequently used in chest disease hospitals, should be improved. Considering the nurses' different knowledge levels on different topics, the development of evidence-based clinical guidelines and protocols is recommended. Basic and continuing education programs should be organized for nurses who play active roles in the field of NIMV application. In this training program, nurses should be informed about what to do before, during, and after NIMV application; what they should pay attention to; and what they are responsible for. In addition, all the equipment should be introduced to them, and their tasks should be determined. In addition to theoretical training, implementation training should also be performed, and it should be ensured that the procedures are diligently practiced.

Ethics Committee Approval: Ethics committee approval was received for this study. Because verbal consensus from all nurses and written consent from hospital directors were obtained.

Informed Consent: Verbal informed consent was obtained from all of the nurses who participated in this study.

Peer-review: Externally peer-reviewed.

Author Contributions: Concept - M.T., Ö.H., F.P., S.A.G., L.D.; Design - M.T., Ö.H., F.P.; Supervision - M.T., F.P., Ö.H.; Resource - M.T., S.A.G., Ö.H.; Materials - M.T., F.P., Ö.H.; Data Collection and/or Processing - M.T., Ö.H., F.P., S.A.G., L.D.; Analysis and/or Interpretation - M.T., F.P., S.A.G.; Literature Review - M.T., Ö.H., S.A.G.; Writer - M.T., Ö.H., F.P., S.A.G., L.D.; Critical Review - M.T., Ö.H., F.P., S.A.G., L.D.

Acknowledgements: We would likely to thank directors of hospital and our participant nurses their role in the completion of this research.

Conflict of Interest: No conflict of interest was declared by the authors.

Financial Disclosure: The authors declared that this study has received no financial support. 


\section{REFERENCES}

1. Saltürk C, Kargın F, Berk Takır H, Adıgüzel N, Güngör G, Balcı M, et al. Yoğun bakım ünitesinde gece noninvaziv mekanik ventilasyon maske uygulama sıklığı. Göztepe Tıp Dergisi 2012; 27: 90-3.

2. Carron M, Freo U, BaHammam AS, Dellweg D, Guarracino F, Cosentini R, et al. Complications of non-invasive ventilation techniques: a comprehensive qualitative review of randomized trials. Br J Anaesth 2013; 110: 896-914. [CrossRef]

3. Utku T. Noninvazif mekanik ventilasyon. Hemşirelikte Eğitim ve Araştırma Dergisi 2006; 3: 24-9.

4. Hill NS. Where should nonventilation be delivered? Respir Care 2009; 54:62-70.

5. Browning J, Atwood B, Gray A. Use of non-invasive ventilation in UK emergency departments. Emerg Med J 2006; 23:920-1. [CrossRef]

6. Vanpee D, Delaunois L, Lheureux P, Thys F, Sabbe M, Meulemans A, et al. Survey of noninvasive ventilation for acute exacerbation of chronic obstructive pulmonary disease patients in emergency departments in Belgium. Eur J Emerg Med 2002; 9: 217-24. [CrossRef]

7. Carlucci A, Delmastro M, Rubini F, Fracchia C, Nava S. Changes in the practice of non-invasive ventilation in treating COPD patients over 8 years. Intensive Care Med 2003; 29: 419-25.

8. Elliott MW, Confalonieri M, Nava S. Where to perform noninvasive ventilation? Eur Respir J 2002; 19: 1159-66. [CrossRef]

9. Oppersma E, Doorduin J, van der Heijden EH, van der Hoeven JG, Heunks LM. Noninvasive ventilation and the upper airway: should we pay more attention? Crit Care 2013; 17: 245. [CrossRef]

10. Antonelli M, Conti G, Rocco M, Bufi M, De Blasi RA, Vivino G, et al. A comparison of noninvasive positive pressure ventilation and conventional mechanical ventilation in patients with acute respiratory failure. $\mathrm{N}$ Eng J Med 1998; 339: 429-35. [CrossRef]

11. Ram FS, Picot J, Lightowler J, Wedzicha JA. Noninvasive positive pressure ventilation for treatment of respiratory failure due to exacerbations of chronic obstructive pulmonary disease. Cochrane Database Syst Rev 2004; 1 : CD004104.

12. Weng CL, Zhao YT, Liu QH, Fu CJ, Sun F, Ma YL, et al. Meta-analysis: noninvasive ventilation in acute cardiogenic pulmonary edema. Ann Intern Med 2010; 152: 590-600. [CrossRef]

13. Demoule A, Girou E, Richard JC, Taillé S, Brochard L. Increased use of noninvasive ventilation in French intensive care units. Intensive Care Med 2006; 32: 1747-55. [CrossRef]

14. Garpestad E, Brennan J, Hill NS. Noninvasive ventilation for critical care. Chest 2007; 132: 711-20. [CrossRef]

15. Keenan SP, Mehta S. Noninvasive ventilation for patients presenting with acute respiratory failure: the raandomized controlled trials. Respir Care 2009; 54: 116-26.

16. Mas A, Masip J. Noninvasive ventilation in acute respiratory failure. Int J Chron Obstruct Pulmon Dis 2014; 9: 837-52.

17. Karakurt Z, Altınöz H, Yarkın T. Noninvasive Positive Pressure Ventilation in Chronic Obstructive Pulmonary Diseases with Acute Respiratory Failure. Yoğun Bakım Dergisi 2004; 4: 50-6.
18. King AC. Long-term mechanical ventilation in the United States. Respir Care 2012; 57: 921-30. [CrossRef]

19. Hess DR. Patient-ventilator interaction during noninvasive ventilation. Respir Care 2011; 56: 153-67. [CrossRef]

20. Hess DR. Noninvasive ventilation for acute respiratory failure. Respir Care 2013: 58: 950-68. [CrossRef]

21. Ursavaş A, Özyardımcı N. Akut solunum yetmezliklerinde noninvaziv mekanik ventilasyon. Uludağ Tıp Fakültesi Dergisi 2003; 29: 55-9.

22. Antonelli M, Pennisi MA, Pelosi P, Gregoretti C, Squadrone V, Rocco M, et al. Noninvasive positive pressure ventilation using a helmet in patients with acute exacerbation of chronic obstructive pulmonary disease: a feasibility study. Anesthesiology 2004; 100: 16-24. [CrossRef]

23. Gonzalez J, Sharshar T, Hart N, Chadda K, Raphaël JC, Lofaso F. Air leaks during mechanical ventilation as a cause of persistent hypercapnia in neuromuscular disorders. Intensive Care Med 2003; 29: 596-602.

24. Fratecielli AT, Lellouche F, L'her E, Taillé S, Mancebo J, Brochard L. Physiological effects of different interfaces during noninvasive ventilation for acute respiratory failure. Crit Care Med 2009; 37: 939-45. [CrossRef]

25. Gregoretti $C$, Confalonieri $M$, Navalesi $P$, Squadrone V, Frigerio $P$, Beltrame $F$, et al. Evaluation of patient skin breakdown and comfort with a new face mask for non-invasive ventilation: a multi-center study. Intensive Care Med 2002; 28: 278-84. [CrossRef]

26. Munckton K, Ho KM, Dobb GJ, Das-Gupta M, Webb SA. The pressure effects of facemasks during noninvasive ventilation: a voluntteer study. Anaesthesia 2007; 62: 1126-31. [CrossRef]

27. Gay PC. Complications of noninvasive ventilation in acute care. Respir Care 2009; 54: 246-58.

28. Dhand R. Aerosol therapy during mechanical ventilation: getting ready for prime time. Am J Respir Crit Care Med 2003; 168: 1148-9. [CrossRef]

29. Branconnier MP, Hess DR. Albuterol delivery during noninvasive ventilation. Respir Care 2005; 50: 1649-53.

30. Schettino G, Altobelli N, Kacmarek RM. Noninvasive positive pressure ventilation reverses acute respiratory failure in select "donot-intubate" patients. Crit Care Med 2005; 33: 1976-82. [CrossRef]

31. Saatci E, Miller DM, Stell IM, Lee KC, Moxham J. Dynamic dead space in face masks used with noninvasive ventilators: a lung model study. Eur Respir J 2004; 23: 129-35. [CrossRef]

32. Schettino GP, Chatmongkolchart S, Hess DR, Kacmorek RM. Position of exhalation port and mask design affect $\mathrm{CO} 2$ rebreathing noninvasive machanical ventilation. Crit Care Med 2003; 31: 2178-82. [CrossRef]

33. Çelikel T. Noninvazif mekanik ventilasyon. Yoğun Bakım Dergisi 2012; 2: 225-45.

34. García-Maribona J, González M, Blanco JM, Monroyt JC. Caring for noninvasive ventilation patients. In: A. Medina, M. Pons, F. Martinón Torres, editors. Non-invasive ventilation in Pediatrics. 2nd ed. 2004; pp. 65-74.

35. Turan G, Şengöz İnan A, Akgün N, Taşçıoğlu J, Göktaş P. The effective usage time of the humidifier/Bactriel filters in the mechanical ventilator circuits. J Clin Anal Med 2011; 2: 46-8. [CrossRef]

36. Schönhofer B, Sortor-Leger S. Equipment needs for noninvasive mechanical ventilation. Eur Respir J 2002; 20: 1029-36. [CrossRef] 